\title{
Hirayama Disease- A Classic Case with Typical MRI Findings
}

\author{
C. Sable ${ }^{1}$, Girish N. K², V. M. Kulkarni ${ }^{3}$ P. Sharma ${ }^{4}$
}

\begin{abstract}
${ }^{1}$ Department of Radiodiagnosis, Dr. D. Y. Patil Medical College, Pune, Maharashtra, India. ${ }^{2}$ Department of Radiodiagnosis, Dr. D. Y. Patil Medical College, Pune, Maharashtra, India. ${ }^{3}$ Department of Radiodiagnosis, Dr. D. Y. Patil Medical College, Pune, Maharashtra, India. ${ }^{4}$ Department of Radiodiagnosis, Dr. D. Y. Patil Medical College, Pune, Maharashtra, India.
\end{abstract}

\section{INTRODUCTION}

Hirayama disease is also called monomelic amyotrophy or juvenile spinal muscular atrophy of the distal upper extremity. There is anterior displacement of dural sac during cervical flexion which impairs the anterior horn cells of the distal cervical spinal cord secondarily. ${ }^{[1,2]}$ it mostly affects males in $2^{\text {nd }}-3^{\text {rd }}$ decades. Clinically, the patient mainly presents with unilateral or bilateral muscular atrophy and weakness of the forearms and hands which is insidious in onset and is slowly progressive. Rarely, autonomic involvement, sensory disturbance and upper motor neuron (UMN) signs like hyperreflexia and hypertonia maybe seen.[3] Pathogenic mechanism is that there is marked asymmetric flattening of the lower cervical cord which is caused due to forward displacement of the posterior wall of cervical canal in flexion. ${ }^{[4]}$ the distinguishing feature of this disease is that after progression for 2 to 4 years it achieves a plateau with spontaneous stabilization. ${ }^{[5,6]}$ It is most commonly seen in Asian countries like India and Japan. ${ }^{[4,7,8]}$ Aetiology of this disease in majority of cases is usually unknown.. Dynamic cervical spine MRI with additional flexion views is a useful diagnostic modality in the evaluation of the imaging findings. Hirayama's disease is also referred to as Monomelic Amyotrophy (MMA), Juvenile NonProgressive Amyotrophy. This is a rare disorder which predominantly affects forearm and hands and is a type of focal lower motor neuron type disease. Early diagnosis and treatment help in reducing the morbidity of the disease.

\section{PRESENTATION OF CASE}

The patient was a 21-year-old male who came to us with history of tremors in left hand from 3 years. The tremors were insidious in onset and gradually progressed to current situation. He also gave history of weakness and cramping of left upper limb. He had also noticed wasting of muscles of left upper limb which was gradually progressive in nature. There was no history of any pain, loss of sensation, diplopia, ptosis, dysphagia, neck pain, trauma, poliomyelitis, fever or exposure to toxins or heavy metals. There was no similar family history or any other neuromuscular disease. The patient's physical examination was normal. Cranial nerves and sensory examination was normal. On motor examination, there was atrophy and weakness of muscles of left upper limb. Deep tendon reflexes were sluggish. Routine blood investigations were within normal limits.
Corresponding Author:

Dr. Girish N. K.

MHADA Colony,

Sharayu Building, 304 4B,

Pimpri, Pune-411018,

Maharashtra, India.

E-mail: giri333@hotmail.com

DOI: $10.14260 / j e m d s / 2019 / 731$

Financial or Other Competing Interests: None.

How to Cite This Article:

Sable C, Girish NK, Kulkarni VM, et al. Hirayama disease- a classic case with typical MRI findings. J. Evolution Med. Dent. Sci. 2019;8(44):3371-3373, DOI: $10.14260 / \mathrm{jemds} / 2019 / 731$

Submission 06-09-2019, Peer Review 20-10-2019, Acceptance 26-10-2019, Published 04-11-2019. 
MRI of cervical spine showed thinning of cervical cord at C5, C6 and C7 levels suggestive of cord atrophy. T2W hyperintensity was noted posterior to the spinal canal extending from C4 to D2 vertebral level with ill-defined cord signal intensity. On flexion contrast images the posterior wall of dural canal is seen displacing anteriorly from C4-D2 with the epidural space filling with intermediate to high T2 signal representing engorged epidural venous plexuses, the cord appears bow strung over the posterior aspect of the vertebral bodies and compressed by the displaced dura. The anteroposterior diameter of the spinal cord at C5 was $68 \mathrm{~mm}$, C6 was $50 \mathrm{~mm}$ and C7 was $41 \mathrm{~mm}$ and at D1 was $57 \mathrm{~mm}$. Ligamentum flavum, inter vertebral disc, facetal joints, paravertebral soft tissues, intervertebral foramina and cranio - cervical junction were normal. Based on these imaging features and clinical examination a diagnosis of Hirayama disease was made.

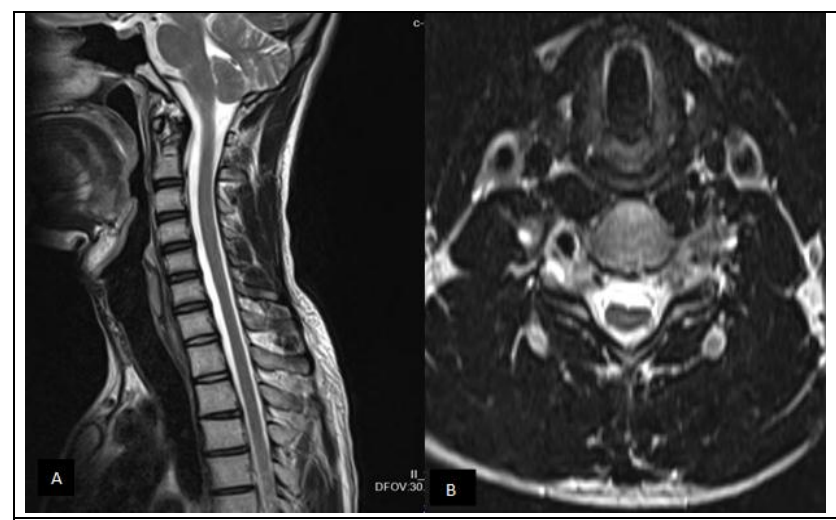

Figure 1. Neutral Position Sagittal (A) and Axial (B) T2W Image Showing Focal Cord Atrophy at C5, C6 and C7 Levels

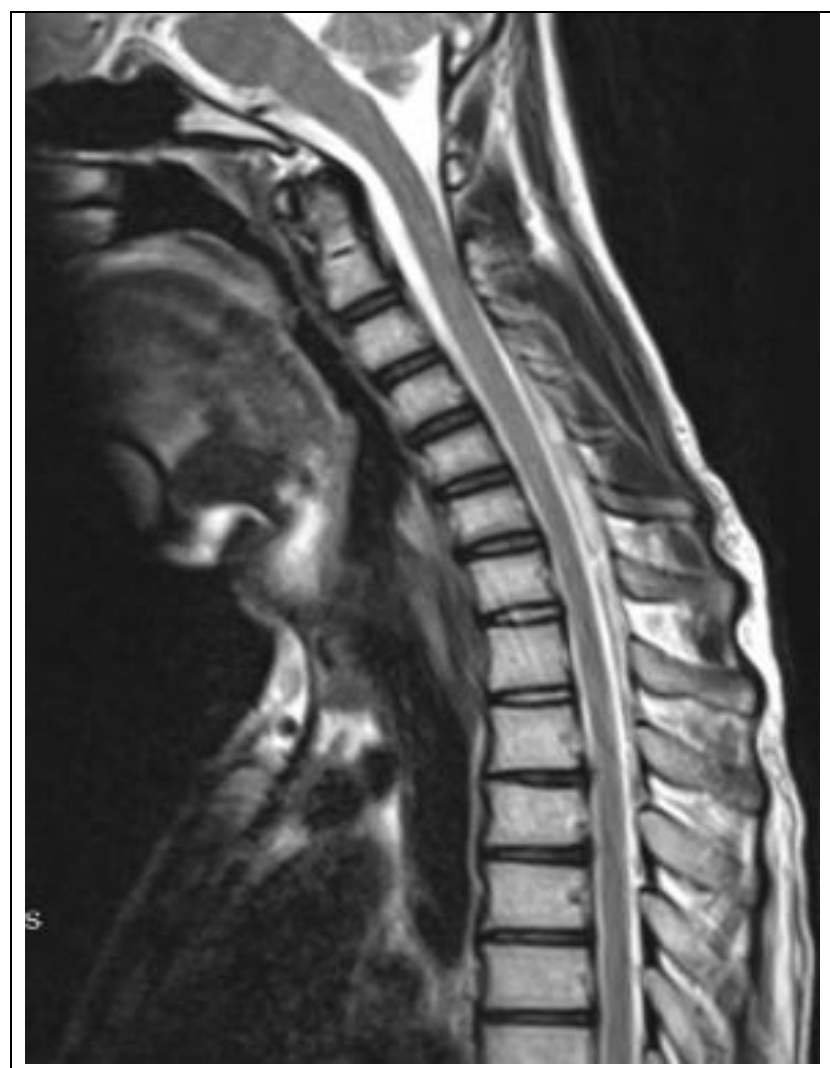

Figure 2. Sagittal Flexion T2W Image. There is Anterior Displacement of the Dorsal Dura (Arrow) causing Compression of the Cal Sac, with a Prominent Dorsal Epidural Compartment (Arrowhead)

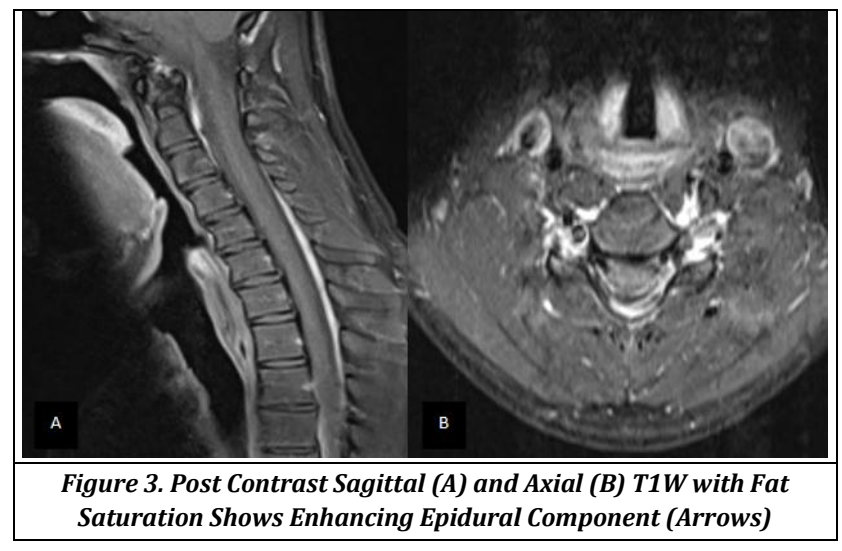

\section{DISCUSSION}

K Hirayama first described HD in 1959 as "juvenile muscular atrophy of the distal upper extremity". Many case reports are published from then from all around the world in literature as "juvenile muscular atrophy of the distal upper extremity, juvenile asymmetric segmental spinal muscular atrophy, and benign focal amyotrophy or monomelic amyotrophy".[3]

HD has a slight male preponderance. Clinically it is characterized by wasting and asymmetrical weakness of upper limb muscles predominantly C7, C8 and T1 myotomes. There is progression for few years followed by arrest of progression with a benign course. Symptoms may include tremors in the fingers which are irregular and coarse, which may worsen transiently on exposure to cold. [3] HD poses a diagnostic challenge due to scarcity of the disease and several atypical reported cases

Táchira et al. ${ }^{[9]}$ outlined specific criteria which include-

1. Muscle weakness which is predominantly distal part with atrophy in forearm and hand.

2. Unilateral upper extremity is involved almost always.

3. Disease onset occurs between years 10 to early 20 s.

4. There is insidious onset of the disease which is gradually progressive for few years which is which shows subsequent stabilization.

5. There is no involvement of the lower extremity.

6. Sensory system and tendon reflexes are normal.

7. Other diseases should be excluded.

MRI is an easy imaging modality and is helpful in revealing various findings on neutral and flexion positioning like atrophy of cervical cord which is focal and localized, asymmetric cord flattening, and the loss of attachment between the posterior dural sac and subjacent lamina have $80 \%$ accuracy. Other findings include parenchymal changes which is seen in the lower cervical cord and abnormal cervical curvature. Most valuable finding in neutral position for diagnosing Hirayama disease is the loss of attachment.[10,11,12]

Spinal dura mater is normally anchored in the vertebral canal at the foramen magnum and the dorsal surfaces of $\mathrm{C} 2$ and $\mathrm{C} 3$ and at the coccyx. Slack of the dura mater normally compensate for the increased length in flexion. But in HD the dural sac is tight and causes posterior dural sac to separate from its subjacent lamina and abnormal cervical curvature (Straight or kyphotic). So, on flexion normal compensation 
cannot happen leading to compression of the cord against vertebral bodies due to anterior shifting of the posterior dural wall which in turn causes disturbances in microcirculation in the anterior spinal artery territory in the lower cervical spinal cord. [1],[2],[13]

Multiple episodes of ischemia and chronic trauma to the spinal cord due to repeated flexion leading to myelopathy which appears as asymmetric lower cervical cord thinning in the MRI. Flexion MRI shows forward migration dura matter wall with enlarged posterior epidural space. On contrast MRI multiple curvilinear flow voids are seen within a crescent shaped hyperintense, epidural mass showing, and uniform enhancement is seen in the posterior epidural space which disappears on neutral position of neck which is due to of posterior internal vertebral venous plexus congestion.[4],[12]

Early diagnosis and treatment with cervical collar therapy to prevent neck flexion is needed as this reduces functional disability and also halts progression of disease.[3] In selected patients' duroplasty, anterior cervical decompression and tendon transfer with reconstruction have shown encouraging results.[12]

\section{DIFFERENTIAL DIAGNOSIS}

- O’Sullivan McLeod

- Flail arm syndrome

- Post-polio syndrome

- Motor neuron diseases

- Syringomyelia

- Amyotrophic lateral sclerosis

- Cervical spondylotic myelopathy

- Spinal cord tumour. [6],[5]

\section{REFERENCES}

[1] Correia de Sá M, Costa $H$, Castro S, et al. A Portuguese case of Hirayama disease. BMJ Case Reports 2013;2013. pii: bcr2013200645.
[2] Yoo SD, Kim HS, Yun DH, et al. Monomelic amyotrophy (Hirayama disease) with upper motor neuron signs: a case report. Annals of Rehabilitation Medicine 2015;39(1):122-7.

[3] Anuradha S, Fanai V. Hirayama disease: a rare disease with unusual features. Article ID 5839761, Case Reports in Neurological Medicine 2016;2016: p. 4.

[4] NarayanaGowda BS, MohanKumar J, Basim PK. Hirayama's Disease - a rare case report with review of literature. Journal of Orthopaedic Case Reports 2013;3(3):11-4.

[5] Aundhakar SC, Mahajan SK, Chhapra DA. Hirayama's Disease: a rare clinical variant of amyotrophic lateral sclerosis. Adv Biomed Res 2017;6:95.

[6] Orsini M, De Freitas MRG, Catbarino A, et al. Upper limb proximal form of benign monomelic amyotrophy: on purpose of 2 cases. Rev Bras Neurol 2008;44(3):13-7.

[7] Gourie-Devi M. Monomelic Amyotrophy of upper or lower limbs. In: Wisen AA, Shaw PJ, eds. Handbook of Clinical Neurology. Elsevier BV 2007: p. 207-27.

[8] Pal PK, Atchayaram N, Goel G, et al. Central motor conduction in brachial monomelic amyotrophy. Neurology India 2008;56(4):438-43.

[9] Tashiro K, Kikuchi S, Itoyama Y, et al. Nationwide survey of juvenile muscular atrophy of distal upper extremity (Hirayama disease) in Japan. Amyotrophic Lateral Sclerosis 2006;7(1):38-45.

[10] Chen CJ, Hsu HL, Tseng YC, et al. Hirayama flexion myelopathy: neutral position MR imaging findingsimportance of loss of attachment. Radiology 2004;231(1):39-44.

[11] Mukai E, Matsuo T, Muto T, et al. Magnetic resonance imaging of juvenile-type distal and segmental muscular atrophy of upper extremities. Rinsho Shinkeigaku 1987;27(1):99-107.

[12] Raval M, Kumari R, Dung AA, et al. MRI findings in Hirayama disease. Indian J Radiol Imaging 2010;20(4):245-9.

[13] Sonwalker HA, Shah RS, Khan FK, et al. Imaging features in Hirayama disease. Neurol India 2008;56(1):22-6. 